\title{
Analysis of a Low-Carbon Development Model in the Context of China's Economic Policy
}

\author{
Boyi Zhang ${ }^{1, \text { a }}$, Guanyu Yan ${ }^{2, b}$ and Hong Xiong ${ }^{3, c}$ \\ ${ }^{1}$ School of Mathematical Science, Peking University, Beijing, 100871, China \\ ${ }^{2}$ Economy and Management Institution, Chang'an University, Xi'an, 710018, China \\ ${ }^{3}$ No.1 Middle School Affiliated to Central China Normal University, Wuhan, 430062, China \\ a 1204302148@qq.com, b615802777@qq.com, ckevinxiong0821@163.com
}

Keywords: Low Carbon Economy Index system, Carbon Emissions, Foreign Direct Investment, Gross Domestic Product, Co-Integration.

\begin{abstract}
There are a large number of economic and political variables that can affect aggregate carbon emissions at the national level. There does not currently exist a global standard for measuring these variables against each other, and comparing them across countries. Like many countries, China is currently exploring different ways to quantify these variables. Our research creates a framework that we call the Low Carbon Economy Index System, and uses a number of variables within that framework to comprehensively evaluate the correlative and causative forces that these variables exert on each other. Our method uses a comprehensive synthesis of data, drawing primarily on official data from the National Bureau of Statistics of China, and is evaluated using a spinodal decomposition test and a Johansen test for co-integration. We have also taken the opportunity to include a number of economic policy recommendations based on the results of our findings.
\end{abstract}

\section{Introduction}

In order to clarify the complicated relationship between economic growth and growth in carbon emissions, this paper will use some econometric methods, including a co-reconciliation hypothesis, causality tests, and spinodal decomposition. The purpose of these methods is to show how economic growth impacts carbon emissions. Our results are as follows: Firstly, Chinese economic growth is highly carbon intensive. Therefore, a carbon pricing scheme would impact Chinese economic growth rates under all foreseeable circumstances. Reforms to Chinese monetary policy would be by far the most effective way of reducing Chinese emissions without impacting growth, producing much lower emissions outcomes than direct or indirect subsidies. Our study suggests that the advantages of setting a carbon price are somewhat offset by the negative impact it would have on Chinese productivity growth. Monetary reforms, by contrast, are very likely to increase total-factor productivity in the real economy. Finally, our examination of the share prices of publicly traded Chinese companies indicated that investors are willing to pay a premium for shares of "low carbon" companies. This could theoretically provide an alternative mechanism for reducing carbon emissions, although currently the low market capitalization of Chinese firms limits the impact of the share price mechanism.

China's share of global carbon emissions is now the largest of any country, accounting for $34.2 \%$ of the total as of 2009. Furthermore, absolute levels of Chinese carbon emissions are not expected to fall even in the very long term, because China has not yet completed the transition to a fully industrialized and urbanized society. We may thus reasonably anticipate continuous increases in Chinese emissions levels. In light of the increasingly influential movement worldwide towards sustainable development and environmental localism, the Chinese central government has pledged to reduce 2020 levels of carbon emissions by 35\% compared to the 2007 emissions rate. However, it is an open question whether this reduction can be achieved without negatively impacting Chinese economic growth rates. As of yet, there is no consensus within the scientific and policy communities 
as to what the impact will be.

Naturally, we cannot take it as a given that carbon emissions automatically increase with economic growth, or that total carbon emissions must always be linked to income. It is entirely possible that as a country becomes wealthier, they may be able to "buy" reductions in their carbon emissions, either through offsets or through advanced "green" technologies. However, there are several reasons why without specifically created economic incentives, carbon emissions will tend to increase linearly with economic growth. Firstly, any economic growth in a sufficiently free market will draw in investors, which will cause still further economic expansion and further growth in carbon emissions. This problem is especially acute in China, since there is some evidence that wealthy countries export their own carbon emissions through increased FDI flows to developing nations. Secondly, economic growth leads to higher incomes and higher levels of available consumer credit. This will generally spur consumer spending (especially in a country like China, where increasing consumption is an explicit government policy.) Consumer durables like vehicles, refrigerators, central heating and air conditioning, and washing machines will all directly contribute to increasing a country's level of carbon emissions.

In addition, as developing countries modernize their financial systems and deepen their capital markets, it is to be expected that investors will seize new opportunities to pool risk, acquire diverse investments, modernize and streamline their acquisitions, and engage in arbitrage. Although one can easily imagine how these activities could increase overall demand in the economy, and therefore increase carbon emissions, there are also ways in which deep and liquid capital markets can moderate the carbon intensity of a country's economic growth. For example, access to capital can allow a firm to permanently increase its investment levels, which may significantly increase the firm's overall productivity. Higher labor productivity should reduce carbon intensity, and therefore reduce the firm's total carbon emissions. Additionally, a modern financial system is strongly correlated with higher quality of corporate governance, because transparent and well-run firms are much more likely to attract investors. Well-run firms, with their forward-thinking and well-educated managers, have statistically lower per-unit carbon emissions than their poorly run competitors: yet another way in which economic growth may actually serve to decrease total carbon emissions in the very long run.

\section{Contextual Background}

Most research on the subject of monetary reform covers topics such as relative exchange rates, inflation and price level targeting, capital flows, and foreign direct investment. There is now a substantial body of literature suggesting that monetary reforms are fundamental to growth in a modern economy. These studies generally contend that implementing reforms will moderate price and exchange rate fluctuations, allowing firms to keep lower levels of inventory, and invest more of their profits. This causes the aggregate capital stock to rise over time. There is therefore a consensus view that only well-developed capital markets in a reformed monetary system can produce the kind of innovation and investment that drives economic growth in the long term.

By contrast, there has been comparatively little research exploring the impact of monetary reform on energy intensity and carbon emissions at the national level. One recent study investigated the impacts of monetary reform on consumer spending in twenty developing countries (including China,) and found that, overall, every step of the reform process was correlated with increased levels of consumer spending. Another study examines the interplay between monetary reform, economic development, and overall emissions levels in the four BRICs: Brazil, Russia, India and China. It tentatively concluded that monetary reforms are correlated with slightly lower levels of "carbon intensity" in the manufacturing sector. On the other hand, several other studies have concluded that, all things being equal, monetary reform programs are generally positively correlated with increased carbon emissions An important mechanism for this was that monetary reform tends to cause increases of Foreign Direct Investment (FDI.) An exploration of how FDI impacts national carbon emissions is beyond the scope of traditional monetary theory.

Studies on the effect FDI flows have on carbon emissions have so far given contradictory results. 
On the one hand, some experts hypothesize that FDI flows will raise the overall level of productivity in the recipient economy, and thus cut carbon emissions on a per-unit basis. On the other hand, the increased growth generated by capital flows may well outweigh the productivity benefits they generate, if they substantially raise the recipient nation's carbon emissions. This author would also like to add that these hypothesized reductions in per-unit carbon emissions flowing from productivity gains are by no means assured. They rely on adequate market incentives to reduce emissions. These incentives do not yet exist in any major economy. Along these lines, future studies should be undertaken to evaluate whether FDI flows are to some extent a mechanism for developed countries to "export" their carbon emissions to places like China, which have relatively weaker regulations on carbon emissions. The existing literature is intriguing but ultimately inconclusive. One of its main defects is that when looking at the relationship between increased spending in the real economy (be it the result of increased FDI flows or government stimulus,) and carbon emissions, researchers have not typically considered the quality of investments. Rather, they have focused strictly on measuring spending on an absolute scale. Another issue is that the official economic data in China are not always reliable, especially with regards to total carbon emissions. Those studying these issues in China, then, are subject to some uniquely thorny constraints.

To cite just one example, most classical economists assume that the majority of bank reserves will naturally become part of the capital stock, i.e. available for productive investment. Even according to official statistics, however, up to $25 \%$ of Chinese bank reserves are "passive," and therefore cannot be considered to be part of the money supply. This indicates that the share of bank reserves to GDP does not give economists an accurate picture of China's true monetary policy. A more effective way of measuring the money supply in China might be to consider the ratio of bank loans GDP: several prominent economists have begun to do exactly this. In order to try to clarify this picture, we used a Johansen test for co-integration, as well as a Granger causality test, to determine the effect of China's monetary policy on carbon emissions. We tested these variables from a binary perspective, i.e. both from the monetary side and from the fiscal side. We also tested for correlations between share prices and carbon emissions.

\section{Data descriptions And Experimental methodologies}

In classical models, economists will measure the effects of changing monetary policy by looking at variables such as aggregate bank loans, changes is asset prices, and bond yield fluctuations. In studying China, we face a more complicated picture, as Chinese securities began to be traded in earnest only in 2008, and we can say that shares in publicly traded companies still comprise a small part of the total Chinese asset market. Therefore, our research does not consider share prices as a significant variable in our analysis. Instead, we use FDI flows as a proxy for share prices in measuring the effects of a changing monetary policy. This is because we can reasonably expect that FDI flows will behave similarly to share prices in response to changing monetary policies, and FDI flows comprise a much larger percentage of China's GDP than publicly traded securities. In order to make our analysis as practical as possible, we have also included overall GDP growth rates as a variable to be tested for causality and co-reconciliation. We note that with the exception of our statistics on FDI flows, all of the official statistics used in our study are published yearly by the National Bureau of Statistics of China, and are subject to quarterly revisions. Our analysis generally indicates that every variable examined, with the exception of monetary intermediation proficiency, is positively correlated with changes in China's monetary policy. As this policy has become more aggressive in recent years, so the correlation has become more pronounced.

Our study examines the impact of China's economic policies on aggregate carbon emissions from two points of view. First, we tested China's changing monetary policy for correlation with aggregate and per-unit carbon emissions. We then performed a similar analysis on government spending; testing increased fiscal stimulus for correlation with increased aggregate carbon emissions. The authors note that the causality tests used were standard methodology. The experimental results shown below demonstrate that monetary policy markers in this original copy 
are A(1) in arrangement. However, some of them don't display a Johannsen type co-integration with carbon outflows, so the standard causality test approach seems to have produced one sided results.

The oddity of the methodology proposed is that it does not necessitate prior-testing for the cointegrating properties of the framework. It therefore dodges the potential difficulties associated with with co-joining tests. We are also aware that unit roots pre-tested for co-combination may display undesirable size bends, which necessitates the utilization of a nonstandard co-integration test. The $\log$ values taken annually for this study are shown in Figure 1.

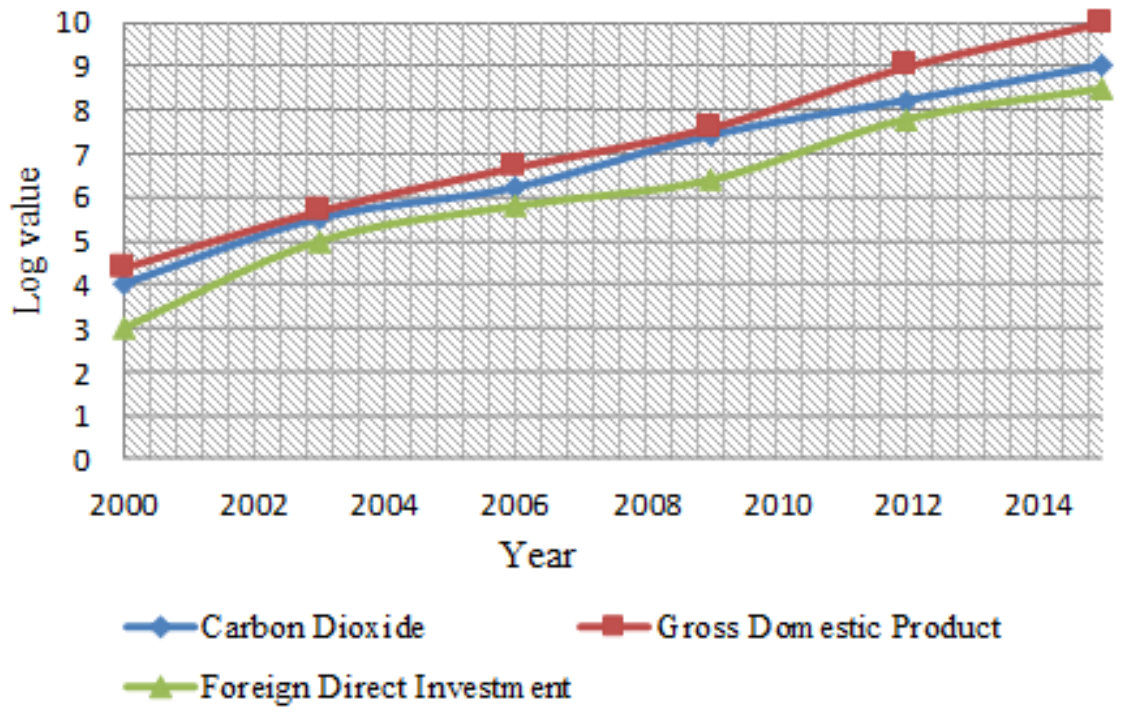

Figure 1 . The log values taken annually for this study

\section{Discussion of Empirical Results}

We have thus examined the co-incorporation of key monetary policy indicators and carbon emissions. Our analysis will explore the long-term interplay between budgetary outlays (i.e. fiscal stimulus) and aggregate carbon emissions, taking into account our hypothesis that there is both correlation and causation present in this relationship. We have proposed this hypothesis because of its advantages over customary co-incorporation. Significantly, we have conducted the increased ADF unit examinations for variables in the original study present in the particular specimen periods with respect to their stationary properties and detailed consequences. We found that that all variables present in the analysis are A(1) in arrangement at or around the $20 \%$ level in their separate sample periods. At that point we took carbon outflows in China as reliably adjustable, and every monetary policy indicator and Gross Domestic Product indicator was tested separately as an autonomous variable. Afterward, we tested all the variables for co-incorporation. Our outcomes clearly shows that aside from Foreign Direct Investment, all other indicators related to either monetary or fiscal policy have at least one co-joining association with carbon emanations at the $10 \%$ level or higher in their individual sample periods. We can thus say with certainty that there is clear long-term correlation between China's monetary policy and aggregate carbon emissions. We were also able to establish that this correlation holds for government expenditures and asset prices as well.

Moreover, all of the variables tested for correlation were then tested for causation. The causal element between increased fiscal outlays and aggregate carbon emissions is very clear. We should note, however, that because of the varying quality of available data, reliable causation cannot be established firmly for all of the indicators. The GDP indicator, for instance, is mainly included in order to establish context.

Nonetheless, certain figures stand out in our results. The effect that China's aggressive monetary and fiscal stimulus since 2009 has had on carbon emissions is particularly clear. We see a clear causation effect at the $20 \%$ level for both monetary policy and total-factor productivity. However, the same effect is much more ambiguous for fiscal outlays at the $20 \%$ level. Finally, we were not able to find any level of causation whatsoever at the $20 \%$ level for either Foreign Direct 
Investment or asset price levels.

We can therefore see very clearly that the incremental increases in aggregate carbon emissions observed in China have their root in various types of economic development. Moreover, it should be noted that by all indications, fiscal outlays by the central government have a relatively small impact on aggregate carbon emissions, so it may be ineffective to pursue reductions in emissions levels by reducing fiscal outlays. The pattern in recent years has been a gentle decline in carbon emissions linked to fiscal outlays; in fact at some point in the near future the correlation may turn negative (i.e. fiscal outlays actually reducing aggregate emissions.) The most promising measures may therefore be found on the monetary side, where a more relaxed policy could allow productive investment to flow towards modernizing and low-carbon sectors of the economy.

Our study also established that the share prices of publicly traded firms are not generally affected by the firm's total carbon emissions. We believe, however, that this has more to do with the qualities of Chinese exchanges than true investor preferences. There are several particular factors that may obscure these preferences. The first is that shares have only been traded in mainland China for a very short period of time, and therefore the culture and regulatory institutions seen in developed countries have not had time to appear. The second is that share prices on Chinese exchanges are influenced not only by economic considerations, but also by political ones. There are also the questions of fraud and embezzlement, which are somewhat more common on mainland exchanges than in developed countries. In addition to that, the Chinese government has intervened directly in mainland exchanges several times, either to repress or depress prices. This adds a dimension of political risk that is unique to mainland investors. Finally, Chinese companies list shares at a much lower rate than their western counterparts, but because of opaque standards of corporate governance, investors are not able to determine how their money is used.

\section{Conclusions and Policy Recommendations}

China is now the largest carbon emitter on the planet, and the goal of reducing 2020 emissions to $35 \%$ below the 2007 level has been announced to the international community with great fanfare. Meanwhile, China's financial system is still relatively underdeveloped, but is making rapid strides towards modernizing to developed-country standards. A key issue in years to come will be whether this modernization will increase or decrease China's chances of meeting the 2020 emissions goals. The econometric framework and empirical methodologies used in our study give us a good starting point for making a few policy recommendations.

Firstly, it is likely that higher fiscal outlays and a more aggressive monetary policy will result fundamentally in increased aggregate carbon emissions. The effect of financial modernization on carbon emissions surpasses that of any other development indicator, on both the monetary and the fiscal sides. Increased private-sector profits in the real economy can be seen to have a similar, if less pronounced, effect. This reflects the way that government policies, business profits, and carbon emissions are all connected on a macro-economic scale. It also suggests that there should be a significant government role in the modernization of China's financial system. The Chinese Central Government should set targets for state-owned lenders to decrease the percentage of non-performing loans, and to use their reserves more efficiently. Furthermore, policies should also be promulgated to increase the productivity of state owned enterprises as a whole. Rapid modernization of the Chinese financial system creates the possibility of creating function markets for carbon emissions, similar to the "cap and trade" scheme currently being implemented in the European Union. These steps will also lead to increased total-factor productivity in the Chinese economy, which will help reduce emissions in the long term.

Finally, our research suggests that investor preferences favoring firms that emit lower levels of carbon are not being accurately reflected in the prices of publicity traded mainland shares. We believe that this is entirely due to the lack of transparency on mainland exchanges. Future government policies should strive to increase standards of corporate governance and transparency, thus allowing investor preferences for "green" firms to be fully reflected in share prices. 


\section{References}

[1] Claessens, S., Feijen, E., 2007. Financial sector development and the millennium development goals. World Bank Working Manuscript No. 89.

[2] Clarke, J., Mirza, S.A., 2006. Comparison of some common methods of detecting Granger noncausality. Journal of Statistical Computation and Simulation 76, 207-231.

[3] Du, Y.F., 2008. On the relationship between regional financial development and economic growth: an empirical study based on the threshold model. Journal of Financial Theory and Practice 10, 33-35 (in Chinese).

[4] List, J., Co, C.Y., 2000. The effect of environmental regulation on foreign direct investment. Journal of Environmental Economics and Management 40, 1-40.

[5] Menyah, K., Wolde-Rufel, Y., 2010. Energy consumption, pollutant emissions and economic growth in South Africa. Energy Economics 32, 1374-1382.

[6] Zhang, X.-P., Cheng, X.-M., 2009. Energy consumption, carbon emissions, and economic growth in China. Ecological Economics 68, 2706-2712.

[7] Dogan, Eyup, and Berna Turkekul. "CO2 emissions, real output, energy consumption, trade, urbanization and financial development: testing the EKC hypothesis for the USA." Environmental Science and Pollution Research 23.2 (2016): 1203-1213.

[8] Ozturk, Ilhan, and Ali Acaravci. "The long-run and causal analysis of energy, growth, openness and financial development on carbon emissions in Turkey." Energy Economics 36 (2013): 262-267.

[9] Boutabba, Mohamed Amine. "The impact of financial development, income, energy and trade on carbon emissions: evidence from the Indian economy." Economic Modelling 40 (2014): 33-41.

[10] Al-Mulali, Usama, and Che Normee Binti Che Sab. "The impact of energy consumption and CO 2 emission on the economic growth and financial development in the Sub Saharan African countries." Energy 39.1 (2012): 180-186.

[11] Shahbaz, Muhammad, et al. "Economic growth, energy consumption, financial development, international trade and CO 2 emissions in Indonesia." Renewable and Sustainable Energy Reviews 25 (2013): 109-121.

[12] Shahbaz, Muhammad, Aviral Kumar Tiwari, and Muhammad Nasir. "The effects of financial development, economic growth, coal consumption and trade openness on CO 2 emissions in South Africa." Energy Policy 61 (2013): 1452-1459.

[13] Peters, Glen P., et al. "Rapid growth in CO2 emissions after the 2008-2009 global financial crisis." Nature Climate Change 2.1 (2012): 2-4.

[14] Zhang, Yue-Jun, et al. "The impact of economic growth, industrial structure and urbanization on carbon emission intensity in China." Natural hazards 73.2 (2014): 579-595.

[15] Shahbaz, Muhammad, et al. "Does financial development reduce CO 2 emissions in Malaysian economy? A time series analysis." Economic Modelling 35 (2013): 145-152. 